\title{
Do endogenous opioids mediate or fine-tune human pain relief?
}

\author{
Marie Eikemo, Guro E Løseth, Siri Leknes \\ Dept. Psychology, University of Oslo
}

\begin{abstract}
This is a commentary on Endogenous opioids contribute to the feeling of pain relief in humans by Sirucek et al, In Press, Pain. We discuss how effects of different magnitudes from human opioid antagonist studies can be interpreted and how the results inform us on the role of the endogenous muopioid system for pain relief and other affective processes in humans.
\end{abstract}

Opioid analgesics bind to the brain's mu-opioid receptors. Endogenous activation of these receptors is also thought to relieve pain. For instance, Zubieta and colleagues [26] found that the higher the endogenous mu-opioid response to prolonged experimental pain in pain-sensitive regions such as the thalamus and insula, the lower the pain was reported by the participants. Painful events are thought to trigger release of endogenous opioids as a regulatory, opponent mechanism $[15,22]$. When endogenous mu-opioid activity is pharmacologically blocked by an antagonist, this regulatory mechanism is inhibited. At first consideration, it may therefore seem surprising that opioid blockade was not found to increase pain by Sirucek et al. in this issue [21].

\section{Automatic and universal opioid pain regulation in humans?}

However, using hidden as well as open infusion of the non-specific opioid antagonist naloxone in dental surgery patients, Levine and Gordon concluded as early as 1984 that increased pain after open naloxone administration was "due to naloxone antagonism of placebo-induced analgesia and [] not an effect of naloxone on the natural history of post-operative pain" ( $\mathrm{p} 755$, [16]). More recent antagonist studies have produced mixed results, with some studies reporting higher pain after opioid antagonism [1] and others finding no reliable change compared to an inactive drug $[2,3]$. Considered together, the available data does not support the existence of a universal and automatically triggered opioidmediated pain regulatory mechanism in the human brain [25].
Could it be that only severe, prolonged or clinically relevant pain triggers such opioidmediated regulation? For instance, the molecular imaging studies that have linked endogenous muopioid activity with downregulation of pain have typically induced sustained facial pain of 20 minutes or more [e.g. 26]. However, studies of post-surgical [16] and chronic low-back pain [3] have reported comparable pain levels after opioid antagonism relative to placebo, suggesting that prolonged clinical pain does not necessarily trigger opioid pain regulation. More wellcontrolled research is needed to determine the conditions under which endogenous opioids relieve pain in the human brain.

\section{Does opioid antagonism decrease the experience of relief?}

The term pain relief refers to two separable experiences: reduced pain, and the experience of relief itself. Changing the speed of pain reduction illustrates the difference: a quick decrease achieves homeostasis faster and is typically experienced as more marked and rewarding than an equally large, but slower decrease of pain [15]. Relief can also be induced by the removal of threat of pain, i.e. without any relief from physical pain. To measure the relief experience, studies often ask participants to rate its intensity or pleasantness on a 0-100 visual analogue scale (VAS). Participants in Sirucek et al's study rated pain in some trials; in others they were asked to report on their experience of relief [21]. A cooling stimulus $\left(25^{\circ} \mathrm{C}\right)$ was applied to the capsaicintreated skin after 30 or 60 seconds of heat calibrated to induce high pain. This approach speeds up the pain reduction and intensifies the 
relief [5], akin to the pleasant cooling effect of a cold shower on a sunburned back. In line with the authors' hypothesis, naltrexone significantly reduced both the intensity and pleasantness of cooling-induced relief. The size of the reduction was modest, 5-10 points on a 0-100 VAS (see also Figure 1). What does this unstandardized effect size tell us about the role of endogenous opioids for pain relief?

\section{Opioid fine-tuning of relief pleasantness}

First, Sirucek et al convincingly demonstrate that the experience of relief after pain offset partly depends on endogenous opioid signalling.

Second, they show that much of the participants' experience of relief is opioid-independent. In line with our lab's $[7,8]$ and other opioid drug studies investigating reward responses [4], full mu-opioid blockade reduced the pleasant experience but did not eliminate it. Together, these results point to a role of endogenous mu-opioids in fine-tuning pleasant experiences from both negative and positive reinforcers. That is, blockade of $90 \%$ or more of mu-opioid receptors by naloxone [17] or naltrexone [13] may remove some enjoyment or hedonic gloss [10], without eliminating participants' ability to judge the overall reward value of a stimulus.

\section{Fine-tuning or full opioid-dependence?}

In contrast to the modest reductions reported for the experience of relief and reward in humans, naloxone was found to completely block reliefrelated hypoalgesia [2], although post-task subjective ratings of relief were unaffected. Complete elimination of behaviours after opioid blockade is also reported in many rodent studies. Intra-ACC blockade with naloxone fully eliminated relief-induced conditioned place preference and dopamine release [18]. Similarly,

\section{How to interpret results from an antagonist study}

- Assuming appropriate study design (blinding, placebo control, sufficient power etc.)

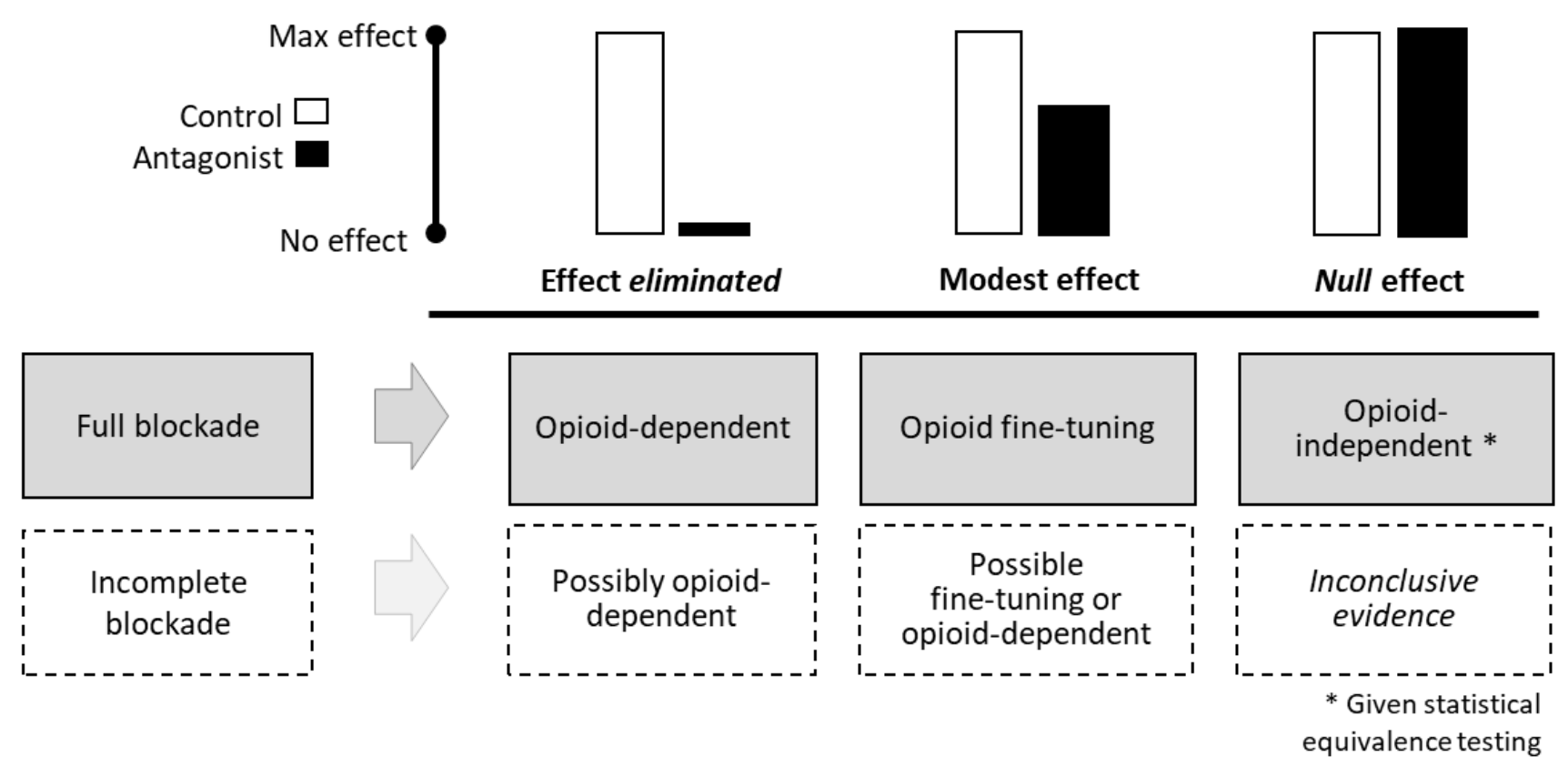

Figure 1. How different type of opioid-antagonist effects can be interpreted depends on the degree of mu-opioid receptor blockade. The interpretations depicted assume adequate study design, including double-blind, randomized, counterbalanced testing, valid measurements, and appropriate statistical power. The findings from Sirucek et al in this issue included a null effect for full blockade of mu-opioid receptors on pain ratings (indicating opioid-independent pain processing) and a modest effect of opioid antagonism on ratings of relief from cooling skin after pain (consistent with opioid fine-tuning of relief). 
preventing mu-opioid signalling eliminated the effects of food deprivation on measures of food palatability [24] and consumption [6]. Such examples of full opioid-dependence may point to a fundamentally different role of endogenous opioid signalling in rodents versus humans. It is also possible that in humans, mu-opioids only fine-tune valuation of rewards, yet are necessary for certain types of hypoalgesia $[2,25]$. In general however, current evidence favours a role of human endogenous opioids in fine-tuning responses to both rewards and pains. With some exceptions, hypoalgesia induced by placebo treatment, stress, or rTMS is typically reduced but not eliminated by opioid antagonism $[9,19,23]$.

\section{Interpreting results from opioid antagonist studies}

Two considerations are key for interpretation of modest or null effects in antagonist studies assessing endogenous opioid function (Figure 1; see also [14] for a checklist of study design requirements): 1) Did the study employ full muopioid receptor blockade (90-100\% binding)? With partial blockade, a weak/null effect might simply reflect that the behaviour relies on a subset of mu-opioid receptors unbound by the antagonist. Hence, only full blockade studies can reliably determine opioid-independence or opioid fine-tuning of an effect. 2) Standard frequentist statistical tests do not permit rejection of the hypothesis (or acceptance of the null hypothesis). In other words, a weak/null effect could result either from a true weak/null effect, or due to insuficcient statistical power. Sirucek et al. commendably employed Bayesian statistics to probe the generalisability of their null effect of antagonism on pain ${ }^{1}$. Across pain measures, the tests provided ancecdotal or moderate support for the "true" absence of a drug effect. Displaying all data points and otherwise increasing transparency, as did Sirucek et al, also aids readers in making their own judgment about the data and results. In sum, this full opioid blockade

\footnotetext{
${ }^{1}$ For those more comfortable with frequentist statistics, equivalence testing is a good alternative to Bayesian analysis of null results [12].
}

data supports the interpretation that endogenous mu-opioids did not modulate pain ratings.

Another recent study illustrates the challenges of interpreting null findings when statistical power is limited. In a commendable translation of rodent research to humans, Fuss and colleagues used naltrexone to test the opioid-dependence of runner's high euphoria [20]. Placebo-treated participants reported a running-induced increase in euphoria of $\sim 24$ points (0-100 VAS). The comparable mood boost in the naltrexone group was of $\sim 18$ points [20]. Hence, runner's high was not eliminated by full mu-opioid blockade, and the group difference was not statistically significant. The authors conclude that runner's high is opioid-independent. Is this interpretation supported by the data?

It is clear that substantial runner's high can be observed after full opioid blockade. Yet, the unstandardized effect size ( $\sim 6$-point reduction in euphoria) matches the modest size of fine-tuning effects reported in the studies reviewed above $[2,4,7-9,21]$. The study only had statistical power to reliably detect larger effects, and did not report equivalence tests. Hence, it seems likely that a larger study might find support for endogenous mu-opioid fine-tuning of runner's high similar to opioid effects on relief after pain.

\section{Reframing endogenous opioids as a system for} fine-tuning human affect

The evidence from human studies using opioid antagonism indicate a role for endogenous muopioids in fine-tuning rather than fully mediating responses to pain and reward. These relatively modest effects, where e.g. pain relief is modulated but not eliminated by full opioid blockade, are somewhat surprising in light of popular conceptualisations of endogenous opioids as the brain's own pain relief and/or feel-good system. They also contrast with the complete elimination of effects observed in some rodent studies, e.g. relief-related dopamine release [18]. Nevertheless, such opioid-mediated fine-tuning 
effects may significantly affect human experience and behavior. Dysregulation of such fine-tuning over time may substantially affect wellbeing [11]. In sum, it is likely that the mu-opioid receptor system works in concert with other neuromodulatory hormones and transmitters to produce and fine-tune hedonic experience of both pains and pleasures.

\section{References}

[1] Anderson WS, Sheth RN, Bencherif B, Frost JJ, Campbell JN. Naloxone increases pain induced by topical capsaicin in healthy human volunteers. Pain 2002;99:207216.

[2] Berna C, Leknes S, Ahmad AH, Mhuircheartaigh RN, Goodwin GM, Tracey I. Opioid-Independent and Opioid-Mediated Modes of Pain Modulation. J Neurosci 2018;38:9047.

[3] Bruehl S, Burns JW, Chung OY, Ward P, Johnson B. Anger and pain sensitivity in chronic low back pain patients and pain-free controls: the role of endogenous opioids. Pain 2002;99:223-233.

[4] Buchel C, Miedl S, Sprenger C. Hedonic processing in humans is mediated by an opioidergic mechanism in a mesocorticolimbic system. eLife 2018;7:e39648.

[5] Cabanac M. Sensory pleasure. Q Rev Biol 1979;54:1-29.

[6] Castro DC, Oswell CS, Zhang ET, Pedersen CE, Piantadosi SC, Rossi MA, Hunker A, Guglin A, Morón JA, Zweifel LS, Stuber GD, Bruchas MR. An endogenous opioid circuit determines state-dependent appetitive behavior. bioRxiv 2021:2021.02.10.430657.

[7] Chelnokova O, Laeng B, Eikemo M, Riegels J, Løseth G, Maurud H, Willoch F, Leknes S. Rewards of Beauty: The Opioid System Mediates Social Motivation in Humans. Mol Psychiatry 2014;19:746-747.

[8] Eikemo M, Biele G, Willoch F, Thomsen L, Leknes S. Opioid Modulation of Value-Based Decision-Making in Healthy Humans. Neuropsychopharmacology 2017;42:1833-1840.

[9] Eippert F, Bingel U, Schoell ED, Yacubian J, Klinger R, Lorenz J, Buchel C. Activation of the opioidergic descending pain control system underlies placebo analgesia. Neuron 2009;63:533-43.

[10] Frijda NH. On the Nature and Function of Pleasure. In: Kringelbach ML, Berridge KC, editors. Pleasures of the brain: the neural basis of sensory rewards. New York: Oxford University Press, 2010. pp. 99-112.

[11] Funder DC, Ozer DJ. Evaluating Effect Size in Psychological Research: Sense and Nonsense. Adv Methods Pract Psychol Sci 2019;2:156-168.

[12] Lakens D, Scheel AM, Isager PM. Equivalence Testing for Psychological Research: A Tutorial. Adv Methods Pract Psychol Sci 2018;1:259-269.
[13] Lee MC, Wagner HN, Tanada S, Frost JJ, Bice AN, Dannals RF. Duration of occupancy of opiate receptors by naltrexone. J Nucl Med 1988;29:1207-11.

[14] Leknes S, Atlas LY. Flawed methodology undermines conclusions about opioid-induced pleasure: implications for psychopharmacology. $\mathrm{Br} \mathrm{J}$ Anaesth 2020;124:e29-e33.

[15] Leknes S, Brooks JCW, Wiech K, Tracey I. Pain relief as an opponent process: a psychophysical investigation. Eur J Neurosci 2008;28:794-801.

[16] Levine JD, Gordon NC. Influence of the method of drug administration on analgesic response. Nature 1984;312:755-756.

[17] Mayberg HS, Frost JJ. Opiate receptors. Quantitative imaging: neuroreceptors, neurotransmitters, and enzymes. New York: Raven Press, 1990. pp. 81-95.

[18] Navratilova E, Xie JY, Meske D, Qu C, Morimura K, Okun A, Arakawa N, Ossipov M, Fields HL, Porreca F. Endogenous Opioid Activity in the Anterior Cingulate Cortex Is Required for Relief of Pain. J Neurosci 2015;35:7264-7271.

[19] Rutgen M, Seidel EM, Pletti C, Riecansky I, Gartus A, Eisenegger C, Lamm C. Psychopharmacological modulation of event-related potentials suggests that firsthand pain and empathy for pain rely on similar opioidergic processes. Neuropsychologia 2017.

[20] Siebers M, Biedermann SV, Bindila L, Lutz B, Fuss J. Exercise-induced euphoria and anxiolysis do not depend on endogenous opioids in humans. Psychoneuroendocrinology 2021;126:105173.

[21] Sirucek L. Endogenous opioids contribute to the feeling of pain relief in humans. PAIN 2021.

[22] Solomon RL, Corbit JD. An opponent-process theory of motivation: I. Temporal dynamics of affect. Psychol Rev 1974;81:119-145.

[23] Taylor JJ, Borckardt JJ, Canterberry M, Li X, Hanlon CA, Brown TR, George MS. NaloxoneReversible Modulation of Pain Circuitry by Left Prefrontal rTMS. Neuropsychopharmacology 2013;38:1189-1197.

[24] Wassum KM, Ostlund SB, Maidment NT, Balleine BW. Distinct opioid circuits determine the palatability and the desirability of rewarding events. Proc Natl Acad Sci U S A 2009;106:12512-7.

[25] Werner MU, Pereira MP, Andersen LP, Dahl JB. Endogenous opioid antagonism in physiological experimental pain models: a systematic review. PLoS ONE 2015;10:e0125887.

[26] Zubieta J-K, Smith YR, Bueller JA, Xu Y, Kilbourn MR, Jewett DM, Meyer CR, Koeppe RA, Stohler CS. Regional mu opioid receptor regulation of sensory and affective dimensions of pain. Science 2001;293:311-315.

\section{Funding}

Marie Eikemo and Siri Leknes acknowledge funding from European Research Council under the European Union's 
Horizon 2020 research and innovation programme (grant agreement no. 802885) to SL, and from the South-Eastern Norway Regional Health Authority (grant number 2018035 to ME and grant 2020087 to SL). 